\title{
Factors Influencing the Sleep Behavior of Primary School-aged Children in Macao
}

\author{
Cindy Sin U Leong ${ }^{1, *}$, Thomas Kwok Shing Wong ${ }^{2}$ \\ ${ }^{1}$ School of Health Sciences, Macao Polytechnic Institute, Macao \\ ${ }^{2}$ Tung Wah College, Hong Kong
}

\begin{abstract}
The school performance of students will definitely be affected if they have inadequate time to sleep. This study explored the factors influencing the sleep health. Fourteen children and their parents were invited to share their experiences, which were obtained through interviews that relied on semi-structured questions. The participating students ranged from grade 1 to grade 6 in primary schools. The 2 major themes discovered were sleep behavior and inadequate sleep. Sleep behavior appeared to be related to personal hygiene before sleep, school bedtime and weekend bedtime, and bedtime habits. Most of the students indicated that they postponed their bedtime on school days during test or exam weeks. School workload, extracurricular activities, and the environment may lead to inadequate sleep. The findings from this study highlight the urgent need for communication with, and education of, parents and school administrators to recognize that proper sleep behavior is essential to better school performance.
\end{abstract}

Keywords Children, Daily Activities, School Workload, Sleep Behavior

\section{Introduction}

Macao, a moderately sized city of 544600 residents, most of them Chinese (97\%), is 29.5 square kilometers in size and located in the southern part of Guangdong Province, 61 kilometers from Hong Kong by ferry. According to the 2009 Education and Youth Affairs Breau, Macao, there were 29,000 students attending primary education. Among the 109 schools, offering pre-primary, primary, secondary and vocational-technical education, there were 59 primary schools for students age ranged from 6 to 14 years old the maximum. The pre-primary or what we called kindergarten followed by a six-year primary education and six-year of secondary education. In addition, these fifteen years of teaching was supported with free education network by the government. These 59 schools include public, subsidized, and private school for the parents to select. Most of the schools have Cantonese for teaching, while English section of some schools will use English as a teaching medium.

Usually, primary students have 5 to 5.5 days per week with 5.5 to 6.5 hours per day. Students will have 7 to 9 sessions daily. According to a survey conducted by the Education and Youth Affairs Bureau (2008), 50\% of students use an average of 2 hours to do their assignments on weekdays while $30 \%$ need 3 hours to finish their assignments. More

* Corresponding author:

suleong@ipm.edu.mo (Cindy Sin U Leong)

Published online at http://journal.sapub.org/ nursing

Copyright (C) 2011 Scientific \& Academic Publishing. All Rights Reserved than $50 \%$ of the students also have private tutors after school. School usually finishes at 4:00 pm and then the private tutors have these students until 6 to $8 \mathrm{pm}$. It is quite common that these children get home after $8: 30 \mathrm{pm}$. Then they have their dinner and personal hygiene before sleep. Sometimes, they even have to review their study on test or exam days before going to sleep. Therefore, it is not amazing that students are hardly have adequate of time to sleep even they are in primary education.

Children nowadays sleep less as a result of their overly hectic lifestyles[1] Preschoolers in Hong Kong did not have adequate sleep when they were compared with children of the same age in Europe[2-3] In addition, various reports show that primary school-aged children are not exempt from the practice of sleeping fewer hours in order to manage their school workloads and extracurricular activities. Not surprisingly, a research study conducted in the United States found that with adequate sleep, children will achieve better school evaluations[4] In addition, studies indicate that insufficient sleep could lead to attention deficit, depression or hyperactivity, or neurological problems[5-8] The risks imposed by sleep deprivation have raised a concern in many provinces in mainland China. As a result, a large campaign was launched to build up efficient sleep behavior by holding an International Sleep Day for younger children in China every year.

The authors of the present study took a qualitative research approach to explore the factors contributing to the sleep behavior of students in primary schools in Macao, a special administrative region of China that borders the South 
China Sea. The aim of this study was to explore the factors that affect the sleep behavior of children on schooldays and weekends and how these factors affect their daily activities and school performance.

\section{Methods}

\subsection{Participants}

Children from primary grades 1 to 6 were recruited for the study. A total of 28 participants, consisting of 7 girls and 7 boys plus 14 parents (the mothers or fathers of the children) were involved. The only criterion for selection was that the children were enrolled in a local primary school (Table 1).

Table 1. Participants in the interviews

\begin{tabular}{|c|c|c|c|c|}
\hline Grade & $\begin{array}{c}\text { Age } \\
\text { (in years) }\end{array}$ & Gender & Parent & Type of School \\
\hline \multirow{2}{*}{1} & 6 & Boy & Mother & $\begin{array}{c}\text { Protestant } \\
\text { (subsidized) }\end{array}$ \\
\cline { 2 - 5 } 2 & 6 & Girl & Mother & Catholic (private) \\
\cline { 2 - 5 } & 7 & Boy & Mother & Protestant (private) \\
\hline \multirow{2}{*}{3} & 7 & Girl & Mother & Catholic (private) \\
\cline { 2 - 5 } & 9 & Boy & Mother & Secular (subsidized) \\
\hline \multirow{3}{*}{4} & 9 & Girl & Father & Protestant (private) \\
\cline { 2 - 5 } & 9 & Goy & Mother & $\begin{array}{c}\text { Protestant } \\
\text { (subsidized) }\end{array}$ \\
\hline \multirow{2}{*}{5} & 10 & Boy & Father & Secular (subsidized) \\
\cline { 2 - 5 } & 10 & Girl & Mother & Protestant (private) \\
\hline \multirow{2}{*}{5} & 11 & Boy & Mother & Catholic (private) \\
\cline { 2 - 5 } & 11 & Girl & Mother & Secular (private) \\
\hline \multirow{2}{*}{6} & 12 & Boy & Mother & $\begin{array}{c}\text { Protestant } \\
\text { (subsidized) }\end{array}$ \\
\cline { 2 - 5 } & 12 & Girl & Father & Catholic (private) \\
\hline
\end{tabular}

\subsection{Interview}

The questions developed in Chinese version for this survey were structured according to the literature review, various sleep questionnaires, and personal daily observations. The questions were drafted and modified with the help of colleagues in different areas of expertise. A sleep expert advised the authors to modify question no. 4 to ask the children to explain whether they had to take medicine before bedtime. Subsequently, two sets of 20 questions were formulated for the study ( 1 for the students and 1 for the parents) that covered the same topics. Most of the questions dealt with how the students perceived their sleep or what their sleep behavior was on school days and on nonschool days. If the students were experiencing inadequate sleep, they were asked to elaborate on what they thought the reasons could be. They were also questioned on how they managed their time during school days and nonschool days. All the questions were open-ended (Tables 2 and 3). All of the students were encouraged to mention details of their sleep patterns. In addition, the parents were asked to describe their children's sleep behavior. Research interviews were conducted in Cantonese.

Table 2. Questions for the students

\begin{tabular}{|c|c|}
\hline 1. & $\begin{array}{l}\text { Please introduce yourself by stating your age, what grade you are } \\
\text { studying, the name of your school, and how many family mem- } \\
\text { bers are living with you. }\end{array}$ \\
\hline 2. & What do you perceive as the function of sleep? Please describe. \\
\hline 3. & $\begin{array}{l}\text { When you have your school time, what is your usual sleep pat- } \\
\text { tern? At what time do you go to bed? Do you need family mem- } \\
\text { bers to remind you to go to bed? Please describe. }\end{array}$ \\
\hline 4. & $\begin{array}{l}\text { Do you have any habits or things you must do, such as taking } \\
\text { medication, taking a shower, changing into pajamas, or any oth- } \\
\text { ers? Please describe in detail. }\end{array}$ \\
\hline 5. & $\begin{array}{l}\text { If you forget the things you need to do before sleep, how would } \\
\text { this affect you? }\end{array}$ \\
\hline 6. & $\begin{array}{l}\text { Please explain how you fall asleep. Think of things such as } \\
\text { holding a teddy bear or other belongings, the need for a family } \\
\text { member to accompany you, lights turned on, listening to music, } \\
\text { or having a story read to you, etc. }\end{array}$ \\
\hline 7. & $\begin{array}{l}\text { How do your family members comment on your sleep beha- } \\
\text { viors? }\end{array}$ \\
\hline 8. & $\begin{array}{l}\text { Please explain whether you are a person who falls asleep easily } \\
\text { or whether you need family members to remind you to go to bed. }\end{array}$ \\
\hline 9. & $\begin{array}{l}\text { Do you remember whether you would have dreams and/or } \\
\text { nightmares? What are the nightmares about? How often do the } \\
\text { nightmares occur? Do you require family members to accompa- } \\
\text { ny you to bed after the nightmare experiences? Please explain. }\end{array}$ \\
\hline 10. & $\begin{array}{l}\text { What are your sleep behaviors over weekends or during holi- } \\
\text { days? Are there any differences compared to weekdays? Please } \\
\text { tell me more about that. }\end{array}$ \\
\hline 11. & $\begin{array}{l}\text { Please describe what happens after you wake up on weekdays. } \\
\text { What time do you wake up, do you need family members to } \\
\text { wake you up, do you have difficulty to wake up, are you usually } \\
\text { late for school, etc.? }\end{array}$ \\
\hline 12. & $\begin{array}{l}\text { How do you feel after you wake up on weekdays? Do you feel } \\
\text { you have had enough sleep or do you experience a lack of sleep? } \\
\text { Please explain. }\end{array}$ \\
\hline 13. & Do you think you have enough time for sleep every day? Why? \\
\hline 14. & $\begin{array}{l}\text { If you think that you do not have enough time to sleep, is inade- } \\
\text { quate sleep causing you any problems, e.g., effect on school } \\
\text { learning, getting along with schoolmates and family members, } \\
\text { emotional control, appetite, and health status, etc. }\end{array}$ \\
\hline 15. & $\begin{array}{l}\text { Do you think there is any correlation between the quality of } \\
\text { sleep and school performance? }\end{array}$ \\
\hline 16. & $\begin{array}{l}\text { Do you have to take a nap at noon or in the afternoon on school } \\
\text { days? How long does the nap last for? What are the reasons for a } \\
\text { noon nap or afternoon nap? Please explain. }\end{array}$ \\
\hline 17. & $\begin{array}{l}\text { Do you need to have a nap even when you do not need to go to } \\
\text { school? Why? }\end{array}$ \\
\hline 18. & $\begin{array}{l}\text { Please talk about the effects your sleep behaviors have on your } \\
\text { family, such as the effect on their rest, work, emotional control, } \\
\text { appetite, health, and other factors. }\end{array}$ \\
\hline 19. & $\begin{array}{l}\text { Are you scolded because of your sleep behaviors or sleep habit? } \\
\text { Why? }\end{array}$ \\
\hline 20. & $\begin{array}{l}\text { How does the family, school, or the social en } \\
\text { your sleep behaviors? Why? }\end{array}$ \\
\hline
\end{tabular}

\subsection{Procedure}

Ethical approval for the study and recruitment process was granted by the Hong Kong Polytechnic University which was a research committee to supervise all the research studies conducted by the students. The interviews were conducted during the academic year, primarily on Friday evenings or weekends. Most of the interviews were conducted at 
participants' homes (one interview was done in a McDonald's restaurant because the respondent insisted on that venue). The interviewing process took 1.5 months to finish. After the initial 12 students (one from each grade) were interviewed, an additional boy and girl from primary grade five were included to ensure data saturation.

Table 3. Questions for the parents

1. $\quad$ Please introduce your child, e.g., his/her age, what grade he/she is studying, the name of his/her school, and how many family members are living together.

2. What do you perceive as the sleep function of children? Please describe.

3. When your child has school in the morning, what is his/her usual sleep pattern? At what time does he/she go to bed, does he/she need family members to remind him/her to go to bed, or what other things he/she should do before bedtime? Please describe.

4. Does your child have any habits or things he/she must do, such as taking medication, taking a shower, changing into pajamas, or any others? Please describe in detail.

5. If your child forgets the things he/she needs to do before sleep, how would this affect him/her?

6. Please explain how your child falls asleep, for instance, holding a teddy bear or other belongings, need a family member to accompany him/her, lights turned on, listen to music or have a story read to him/her, etc.

7. How do you comment on your child's sleep behaviors?

8. $\quad$ Please explain whether your child is a person who falls asleep easily or a child who needs family members or other persons to remind him/her to go to bed.

9. Do you remember whether your child has dreams, and/or nightmares? What are the nightmares about? How often do the nightmares occur? Does the child require family members to accompany him/her to bed after the experience? Please explain.

10. What are your child's sleep behaviors like on weekends or holidays? Are they any different compared to weekdays? Please tell me more about that.

11. Please describe what happens after your child wakes up on weekdays, such as what time your child wakes up, does he/she need family members to wake him/her up, have difficulty to wake up and is late for school, etc.

12. How do you feel about your child after he/she wakes up on weekdays? Do you feel he/she has had enough sleep or lack of sleep? Please explain.

13. Do you think he/she has enough time for sleep every day? Why?

14. If you think that he/she does not have enough time for sleeping, does inadequate sleep cause him/her any problems, e.g., effect on school learning, getting along with schoolmates and family members, emotional control, appetite, and health status?

15. Do you feel there is any correlation between the quality of your child's sleep and his/her school performance?

16. Does your child have to take a nap at noon or in the afternoon on school days? How long does the nap last for? What are the reasons for a noon nap or afternoon nap? Please explain.

17. Does your child need to have a nap even if he/she does not need to go to school? Why?

18. Please talk about the effects your child's sleep behaviors have on the family, such as on their rest, work, emotional control, appetite, health, and other factors.

19. Do you want to scold your child because of his/her sleep behaviors or sleep habits? Do you want to change the behaviors? Why?

20. How do you perceive the influence the family, school, or the social environment has on the sleep behaviors of your child? Why?

\subsection{Data Analysis}

The conversations were audiotaped and then transcribed verbatim for analysis after each interview. Each participant was given a code (for example, A01 for the first interviewee,
A02 for the second). The transcribed data of every participant was read and reread to collect the significant points for coding, categorizing, and selection of themes. When similar or identical items were found in most or all of the individual transcriptions they were grouped into concepts, which were then examined to determine themes.

\section{Results and Discussion}

The numbers of family members were ranged from four to five members including the participant. Being two participants mentioned the function of sleep was to have the body rest, and the other 12 participants were not sure. Family members agreed that their children's sleep behavior was much influenced by the family, school and the environment. Adequate sleep and school performance is quite correlated. Two common themes emerged from the data: sleep behavior (Figure 1) and insufficient sleep (Figure 2). The concepts and subconcepts underlying these themes are shown in the 2 figures and are described below.

\section{Sleep behaviour of the children}

\section{First concept: Personal hygiene before sleep}

Question 4 dealt with personal hygiene before sleep (Tables 2 and 3). For both groups, the interviewers explored this area in detail. The children mentioned that they mostly had their shower before or after dinner, with the routine usually determined by the parents. An 8-year-old boy stated, "No shower before bedtime for having shower right after school" (in other words, because he showered right after school he did not shower at bedtime). They all changed into clean clothes before bed. A 10-year-old boy said, "Must brush teeth before bedtime." According to experts, sleep hygiene includes practices that promote quality sleep time[9-12].

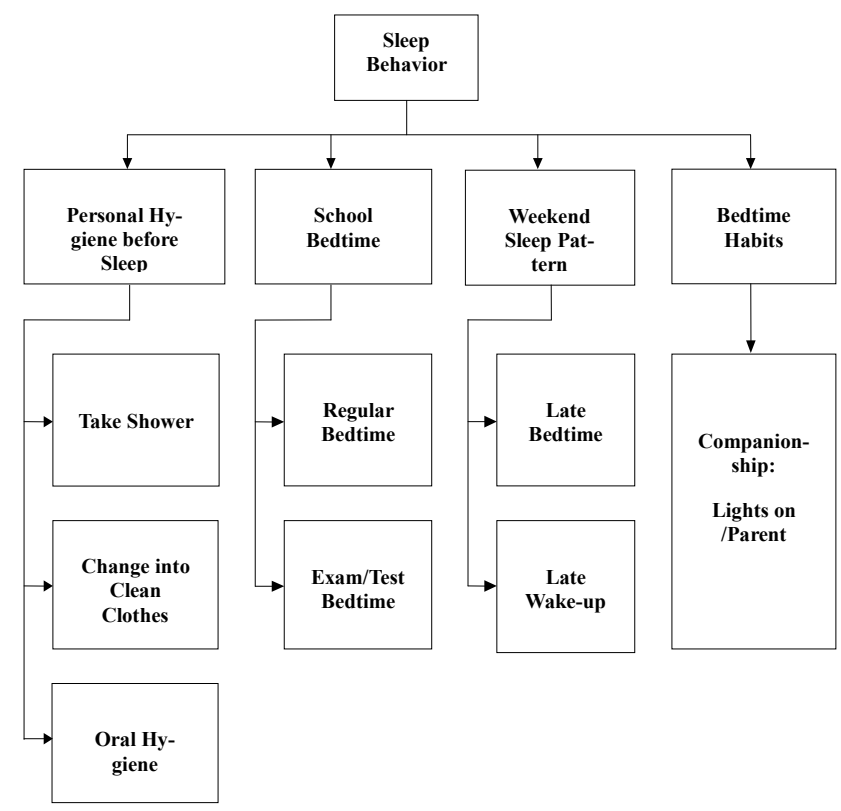

Figure 1. Classification of sleep behaviour

Sleep hygiene, irrespective of whether it is good or bad, 
involves practices that help people to initiate bedtime comfortably[13] Events or actions to encourage falling asleep easily comprise one of the 3 basic principles for sleepers (the two others were environment and events or actions to avoid)[12] A warm bath to wind down the mind is a method to relax the body from daily work and is recommended, while skipping evening meals before bedtime is not recommended[14] Participants in the present study said they would put on clean clothes after having a shower. Doing that would also help the body be fresh and clean for sleep. Brushing teeth, in this study, was a habit that was regulated by parents, who did not want their children to suffer tooth decay. A mother mentioned that even when her children were sometimes too tired to brush their teeth, they would rinse their mouths at bedtime. Studies have mentioned that adoption of good and regular sleep practices may be able to treat sleep initiation difficulties[15-16]

\section{Second and third concepts: School and weekend bedtimes}

The students indicated that if they did not have a test or examinations during the week, their usual bedtime would be around 22:00 to 22:30 (10 PM to 10:30 PM). Most parents recommended this as the ideal time if the child had to wake up around 07:00. Parents controlled the bedtime of their children, and they would remind them of their bedtime once it had arrived. The mother of an 11-year-old boy stated that around 22:30 she would remind her son to go to bed. A dad stated that although even an adult needed 6 to 8 hours of sleep, his child had only 8 hours of sleep. Parents said that when there was no need to get up early on Saturdays and Sundays, children would be allowed to go to bed later so that they could have enjoyable entertainment time such as playing computer games, watching videos, or reading stories. An 11-year-old girl said she would watch the late-evening TV programs with her mummy. Her mother noted: "She went to bed around 23:30 last night and then woke up at 11:00 AM today ..." The mother of a 6-year-old girl stated, "Usually, bedtime is at 22:00 PM...holidays or weekends, let them (the girl and her brother) (go to) sleep at 23:00 PM..."

From the respondents' descriptions, clearly the bedtime of primary school students in Macao on school days is mostly managed by their parents. It also appears that set times of going to bed at night and getting up in the morning are fairly regulated. However, during test or examination weeks, parents would rather have their children finish all their studies before going to sleep, which would result in bedtime being delayed. This phenomenon has been reported in previous research[17] According to some researchers[12,18], bedtime is not just that moment of actually lying down on the bed; indeed, it has been stated that bedtime begins at least 30 to 60 minutes before going to bed[17] Moreover, one sleep expert has stated that bedtime is the period of 1 or 2 hours before going to bed[9] Regular and consistent bedtime is essential on school days and on weekends, in order to have positive effects in children's daytime learning and activities[19-20]

Sleep experts agree that children are too excited to calm down and relax enough to fall asleep immediately, especially on weekends when they could enjoy the most exciting moments they had been waiting for the whole week. Doing favorite activities excites children so much that they might have a hard time falling asleep even if they went to bed at midnight. If this happens, they would wake up very late the following day. Some sleep experiments have suggested that even children between the ages of 6 and 12 years tend to "morningness"[21] (i.e., to be more active and alert in the morning than at other times of the day). If true, primary school children have a biological need to go to bed early and rise early. According to some sleep experts in the USA, children between the ages of 6 and 12 years should have at least 10 hours of sleep[22]

On average, the children in the present study went to bed around 22:00 and woke up around 7:00, and thus overall they got 1 hour less than the recommended amount of sleep. During the interviews it became apparent that the children thought that they were not getting enough sleep on weekdays. One mother believed that 9 hours of sleep for her 6-year old was adequate, but the other parents did not share her view, as their children were reluctant to get up in the morning and needed to be reminded several times.

\section{Fourth concept: Bedtime habits}

The participants, even the boys, indicated that they liked having their parents' company, although the rate of parents or caregivers accompanying children to bed in Western countries is only around $23 \%[23]$ Children in the study felt comfortable and relaxed with an adult around. It was primarily their mothers who accompanied them at bedtime, and during this time they would usually talk about their school performance. The mother of an 8-year-old boy stated: "Three sleep together...his sister...storytelling sometimes or shared school daily news..." If the participants had to go to bed on their own, they preferred a dim light. The mother of a 9-year-old girl said: "No need parent companionship but need light on... no music needed..." A dim light was mostly demanded by girls. Some participants preferred to have bedtime with siblings so that they could chat. However, a 10-year-old girl did not feel happy about sleeping with her younger sister, who was only in kindergarten. Her sister usually went to bed later than she did, as she did not have to wake up early for class.

Judging from the participants' descriptions, their sleep habits were quite different from those reflected in the literature review. Studies elsewhere imply that most children like to have stuffed animals or toys for companionship. They also prefer to have their favorite pyjamas, as well as soft music, as this makes it easy for them to fall asleep[1, 24-26]

\section{Insufficient sleep of the children}

The second theme, insufficient sleep (Figure 2), included four concepts and ten suconcepts as summarized below.

\section{First concept: School workload}

School workload was the first concept for theme no. 2, "insufficient sleep." Here, school workload refers to the huge amount of school assignments and assessments, which 
"stress out" the children. The children reportedly needed to memorize lots of new information every week, and they occasionally had to use the Internet to do assignments. When going online they were sometimes distracted by other information and then wasted a good deal of time. As a result, they sometimes did not have enough time to do any other assignments. Some students who did not study in the popular Chinese schools did not face such heavy workloads and were not that "stressed out." Mostly, public or government school with free education system was not forcing students to learn the knowledge beyond their primary grade as well as the students attended schools where English was used as the medium of instruction. Some parents complained that the schools did not properly coordinate the tests and that their children had to study for 2 or 3 tests on 1 day in addition to finishing their normal homework. The mother of an 11 -year-old boy said that it would be "better to arrange one test daily." The children in schools that used English as the language of instruction did not have a heavy workload, and so they usually had regular bedtimes. A 6-year-old girl stated, "If too much homework...too many things to remember, my little brain is tied up...takes longer to fall asleep..." A 12-year-old girl said: "No fixed time to bed because too much homework".

Many studies have shown that the time children spend in school and at home on studying and homework is quite long. Indeed, in China it may take around 8 to 9 hours to learn and finish the required work daily[27-30] Not surprisingly, the children are not able to keep up such a heavy schedule. Even the government of mainland China has deemed it fit to require that all secondary school students have only 7 hours of learning, 1 hour for playtime, and at least 9 hours of sleep[30] In China, a primary school student normally attends school for almost 7 or 8 hours each day. The time a student spends at school is equal to an adult's working time, but the children are required to keep on working after they go home. A research survey conducted in China found that $78.87 \%$ of the students were still occupied by studies on Sundays[27] The authors also discovered that in the popular schools the children needed more than 10 hours daily for their studies. One study, conducted more than 2,000 USA children[19], also showed that too much homework (46.5\%) and of too much stress $(42.0 \%)$ would definitely prevent to have adequate time of sleep.

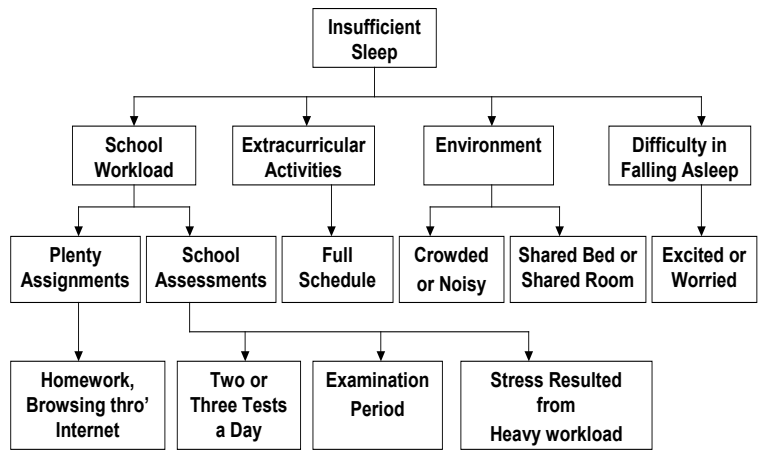

Figure 2. Classification of insufficient sleep
Second concept: Extracurricular activities

Nowadays many parents require their children to attend different extracurricular activities after school or on weekends, and many children have full extracurricular schedules. A 7-year-old girl had a schedule that read like this: ballet lessons on Monday and Wednesday, art lesson on Saturday, and piano lesson on Sunday. An 11-year-old boy had soccer lessons three times a week and swimming lessons twice a week. Because the boy loved soccer so much, he did not complain about the many activities, although he did not like the swimming lessons. Two of the girls mentioned above complained that they had little time to read their favorite storybooks. As a compromise, their parents allowed them to postpone their bedtime so that they could satisfy their "reading hungers". In a report from the US, about $60 \%$ of students listed reading as a bedtime habit[22] According to a study[19], $68.34 \%$ of the participants had daily exercise even no specific of exercises was mentioned. They agreed that exercise helped them to sleep better. However, balance point should be looked at.

\section{Third concept: Environment}

Many participants had to share bedrooms with their siblings, parents, or grandparents. Some even had to share an individual bed with their brothers or sisters. A 6-year-old girl complained: "Like yesterday, little brother woke me up when he was playing and laughing loudly in the living room..." A 9-year old boy said: "Share bedroom with parents...sleep in my bed." According to sleep experts, a bedroom should not have a TV set or a computer that could disturb the children or delay their falling asleep[9] In the present study, authors found that even when there was no TV in the bedroom, the volume of the TV in the living room would sometimes be loud enough to keep the children from falling asleep, as most apartments in Macao are quite small.

\section{Fourth concept: Difficulty in falling asleep}

An 11-year-old boy said: "Like the following day has a party in school...it's real hard to fall asleep." In the USA, a research survey found that $30 \%$ of children had difficulty in falling asleep, that is taking more than 30 minutes to fall asleep can be defined as having difficulty in falling asleep [31] Both external and internal factors could induce someone to stay conscious of her/his surroundings and thus have trouble falling asleep[32]

External factors can be described as any activity that evokes emotional excitement in the child, such as a test, a school celebration, or a change in the relationship between the child and his/her friend(s). In addition, a change in a regular pattern could evoke emotional excitement $[1,10]$ Internal factors are those that arise from or are inherent to the personal development of the child. A history of difficulty in falling asleep could be because of an unhappy bedtime experience, traumatic childhood experiences, and illnesses such as having breathing difficulty, depression, epilepsy, or neurological problems, or dysfunctional health development, all of which could cause children to have difficulty in falling 
asleep[33-42] The most major factors that correlated to difficulty in falling asleep were irregular bedtime, stress out, TV watched and excited activities[19,43] In the study, greater than $25 \%$ of participants admitted watching TV and having exercise before bedtime may cause stimulation and prevent them initiation to sleep not easier[19].

\subsection{Limitations}

In terms of limitations to this study, we note that most of the participants likely came from the same social background, mostly from the middle class. One or two children mentioned that they were on medication when they were sick such as with coughing and fever. In addition, the rather small size of the sample probably limits its generalizability. Further research with more students would be required to investigate the sleep behaviors of primary school students in Macao as well as the impact of insufficient sleep on this population.

\subsection{Conclusions}

Based on this study, we can tentatively conclude that primary school students in Macao have good personal hygiene before sleep but that heavy school workloads as well as abundant extracurricular activities are often barriers to their getting enough sleep. Being young children, they listened to their parents and therefore had a regular bedtime unless they were tied down with a heavy school workload or with tests and examinations. Liberal parents would reward their children by postponing bedtime on weekends and holidays to allow their children to engage in their favorite activities, such as playing computer games and watching TV. This would result in wake-up time being later on weekends, even though the children still had many activities on the weekend.

We found that children in Macao are quite different from the children who were the focus of other research studies. The result showed that Macao children prefer the company of parents or caregivers at bedtime and that they enjoy this time with adults, who in turn get an insight into the children's performance in school. Our study also indicates that if these children cannot have adult companionship, they prefer to have a light on, as they are scared of the darkness. In contrast, Western children mostly go to sleep independently in their own bedrooms. Macao is a small city, and the apartments are not quite spacious enough to provide children with their own bedrooms. Many children in this city need to share a bedroom or a bed with their siblings, parents, or grandparents. The bedtime rituals of other family members with different bedtimes definitely affect these young children, who have a biologically based desire to go to sleep early. Although environmental factors could have a great influence on the quality of sleep, we found that the Macao students did not complain about those environmental factors that affected their sleep; they just complained about having too many extracurricular activities after school on weekdays and on weekends.

Unfortunately, these activities were all scheduled by their parents, and the children could not do anything about it, although their congested schedules sometimes caused stress. Clearly, the heavy school workload, with tons of assignments, tests, and examinations, causes these children to have difficulty in falling asleep. All the participants stated that they had inadequate sleep, even if they went to bed at $10 \mathrm{PM}$ and woke up around 7 AM. Further research is needed to investigate whether all other primary school students in Macao have a sleep pattern that results in an actual sleep time of less than the 10 hours of sleep per day suggested by the National Sleep Foundation.

School administrators, educators, and health care staff should be conscious of the phenomenon of inadequate sleep when they are called upon to consult with so-called "naughty students." Physical, biological, and development abnormalities in these students should be viewed and investigated in the context of inadequate sleep, especially if the child has symptoms of not getting enough sleep. Poor school performance can sometimes be ascribed to inadequate sleep or sleep deprivation. Most health care providers inadvertently neglect this important issue when trying to find underlying reasons for unexplained health conditions or poor school performance in students.

\section{AKNOWLEDGEMENTS}

The authors would like to thank the Macao Polytechnic Institute for funding this study (RP/ESS-05/2007). The author would also like to appreciate all the students and their parents' invaluable contributions in the interviews.

\section{REFERENCES}

[1] Leger, D., and Pandi-Perumal, S.R., 2007, Sleep disorders: their impact on public health, Informa Healthcare, London, $1-17$

[2] Hong Kong Health Department Website. Available at: http://www.encyclopedia.com/doc/1099-sleep.html. Accessed February 25, 2010

[3] Apple Daily News, 2008, New discovery in a world's survey: the sleep of Hong Kong babies was the worst (in Chinese), 4(1), A1

[4] Wolfson, A.R., and Carskadon, M.A., 1998, Sleep schedules and daytime functioning in adolescents, Child Dev. 69(4), $875-887$

[5] Didden, R., Korzilius, H., van Aperlo, B., van Overloop, C., and de Vries, M., 2002, Sleep problems and daytime problem behaviours in children with intellectual disability, J. Intellect Disabil. Res., 46(Pt 7), 537-547

[6] Kirov, R., Kinkelbur, J., Heipke, S., and et al., 2004, Is there a specific polysomnographic sleep pattern in children with attention deficit/hyperactivity disorder? J. Sleep Res., 13(11), 87-93

[7] Meijer, A.M., Habekothe, H.T., and van den Wittenboer, G.L., 
2001, Mental health, parental rules and sleep in pre-adolescents, J. Sleep Res., 10(4), 297-302

[8] Shang, C.Y., Gau, S.S., and Soong, W.T., 2006, Association between childhood sleep problems and perinatal factors, parental mental distress and behavioral problems, J. Sleep Res., $15(1), 63-73$

[9] Courtenay, A., 1990, Natural Sleep: How to Beat Insomnia without Drugs. Northampton, England: Thorsons Publishers Limited, 48-130

[10] Reite, M., Ruddy, J., and Nagel, K., 2002, Evaluation and Management of Sleep Disorders (3rd ed), London: American Psychiatric Publishing, Inc., 216-217

[11] Shneerson, J., 2005, Sleep Medicine: A Guide to Sleep and Its Disorders (2nd edition). Malden, Massachusetts: Blackwell Publishing, 1-53

[12] Stores, G., 2001, A Clinical Guide to Sleep Disorders in Children and Adolescents. New York: Cambridge University Press, 43-54.

[13] Durmer, J.S., and Chervin, R.D., 2007, Pediatric sleep medicine. Continuum Lifelong Learning Neurol., 13(3), 153-200

[14] Bulck, V.D., 2004, Television viewing, computer game playing, and internet use and self-reported time to bed and time out of bed in secondary-school children. Sleep, 27(1):101-104

[15] Owens, J.A., 2008, A clinical overview of sleep and attention-deficit/hyperactivity disorder in children and adolescents, J. Can Acad Child Adolesc Psychiatry, 18(2), 92-102

[16] Weiss, M.D., Wasdell, M.B., Bomben, M.M., Rea, K.J., and Freeman, R.D., 2006, Sleep hygiene and melatonin treatment for children and adolescents with ADHD and initial insomnia, Journal of the American Academy of Child and Adolescent Psychiatry, 45(5), 512-519

[17] Poceta, J.S., and Mitler, M.M., 1998, Sleep Disorders: Diagnosis and Treatment. Totowa, New Jersey: Humana Press, $17-39$

[18] Thorpy, M.J., and Yager, J., 2001, The Encyclopedia of Sleep and Sleep Disorders (2nd ed). New York: Facts on File, Inc., 200-235

[19] Noland, H., Price, J.H., Dake,J., and Telljohann, S.K., 2009, Adolescents' sleep behaviours and perceptions of sleep, J. School Health, 79, 224-230

[20] Peters, J.D., Biggs, S.N., and Bauer, K.M., 2009, The sensitivity of a PDA-based psychomotor vigllance task to sleep restriction in 10-year old girls. J. Sleep Res., 18(2), 173-177

[21] Ahmed, I., Thorpy, and M.J., 2007, Classification of sleep disorders. Continuum Lifelong Learning Neurol., 13(3), $13-30$

[22] National Sleep Foundation: Sleep in America poll 2004, Available at: http://www.sleepfoundation.org, Accessed January 17, 2008

[23] National Sleep Foundation Website. http:// www. sleepfoundation.org. Accessed March 15, 2008

[24] Carskadon, M., Bradley Hasbro Children's Research Center. Lack of sleep can affect athletic performance in teens.
Available at: http://proquest.umi.com /pqdweb? in$\mathrm{dex}=33 \&$ sid $=2 \&$ srchmode $=1 \&$ vinst $=$ PROD $\&$ fmt $=3 \&$ star. Accessed November 8, 2007

[25] Dowshen, S., KidsHealth: All about sleep. Available at: http://kidshealth.org/parent/general/sleep/sleep.html. Accessed January 16, 2008

[26] Owens, J.A., Spirito, A., McGuinn, M., and Nobile, C., 2000, Sleep habits and sleep disturbance in elementary school-aged children. J. Dev Behav Pediatr, 21(1), 27-36

[27] Li, X., Wang, H., Xu, R., and et al., 2000, The relationship between temperament and sleepy behavior in preschool children. J. Chin Med Behav Sci. (in Chinese), 9(3), 215-223

[28] Liu, X., Liu, L., Owens, J.A., and Kaplan, D.L., 2005, Sleep patterns and sleep problems among schoolchildren in the United States and China, Pediatrics, 115(1 Suppl), 240-250

[29] Qian, H.Z., and Yu, W., 2004, Epidemological study of sleep behavior in Guangzhou of children aged 2-12 years. J. Appl Clin Pediatr. (in Chinese), 19(12), 1078-1080

[30] Zhou, K., Yu, X.M., and Ye, G.J., 1997, School assignment workload causing students behaviours problems in a secondary school, Chin Sch Health. (in Chinese), 18(3), 208-209

[31] Bates, J.E., Viken, R.J., Alexander, D.B., Beyers, J., and Stockton, L., 2002, Sleep and adjustment in preschool children: sleep diary reports by mothers relate to behavior reports by teachers. Child Dev., 73(1), 62-74

[32] Montgomery, E., and Foldspang, A., 2001, Traumatic experience and sleep disturbance in refugee children from the Middle East. Eur J. Public Health, 11(1), 18-22

[33] Bader, K., Schafer, V., Schenkel, M., Nissen, L., Kuhl, H.C., and Schwander, J., 2007, Increased nocturnal activity associated with adverse childhood experiences in patients with primary insomnia. J Nerv Men Dis., 195 (7), 588-595

[34] Gordon, J.E., Hughes, M.S., Shepherd, K., and et al., 2006 Obstructive sleep apnoea syndrome in morbidly obese children with tibia vara, J. Bone Joint Surg Br., 88(1), $100-103$

[35] Li, L., Mu, C., Wang, R., and et al., 2004, Sleep problems and related factors of elementary school students. J Chin Psychol Health. (in Chinese), 18(9), 613-616

[36] Luo, X., Li, X., and Wan, G., 1999, Epidemiological survey of sleep disorders in 4-16 year-old children/adolescents in Hunan province, Chin J Psychol Hyg, (in Chinese), 13(3), 129-130

[37] Mulvaney, S.A., Goodwin, J.L., Morgan, W.J., Rosen, G.R., Quan, S.F., and Kaemingk, K.L., 2006, Behavior problems associated with sleep disordered breathing in school-aged children-the Tucson children's assessment of sleep apnea study, J Pediatr Psychol., 31(3), 322-330

[38] Neubauer, D.N., 2003, Understanding Sleeplessness: Perspectives on Insomnia. Baltimore, Md: The Johns Hopkins University Press, 19-117

[39] Paavonen, E.J., Nieminen-von Wendt, T., Vanhala, R., Aronen, E.T., and von Wendt, L., 2003 Effectiveness of melatonin in the treatment of sleep disturbances in children with Asperger disorder. J Child Adolesc Psychopharmacol., 13(1), 83-95 
[40] Rona, R.J., Li, L., Gulliford, M.C., Chinn, S., 1998, Disturbed sleep: effects of sociocultural factors and illness. Arch Dis Child., 78(1), 20-25

[41] Wilson, S., Argyropoulos, S., 2005, Antidepressants and sleep: a qualitative review of the literature. Drugs. 65(7), 927-947
[42] Wirrell, E., Blackman, M., Barlow, K., Mah, J., Hamiwka, L., 2005, Sleep disturbances in children with epilepsy compared with their nearest-aged siblings. Dev Med Child Neurol., 47(11), 754-759

[43] Ivanenko, A., and Patwari, P.P., 2009, Recognition and management of pediatric sleep disorders, Primary Psychiatry, $16(2), 42-50$ 